\title{
The Role of Residual Stresses in the Performance and Durability of Prestressing Steel Wires
}

\author{
J.M. Atienza • J. Ruiz-Hervias • M. Elices
}

\begin{abstract}
Residual stresses developed during wire drawing influence the mechanical behavior and durability of steel wires used for prestressed concrete structures, particularly the shape of the stress-strain curve, stress relaxation losses, fatigue life, and environmental cracking susceptibility. The availability of general purpose finite element analysis tools and powerful diffraction techniques (X-rays and neutrons) has made it possible to predict and measure accurately residual stress fields in cold-drawn steel wires. Work carried out in this field in the past decade, shows the prospects and limitations of residual stress measurement, how the stress relaxation losses and environmentally-assisted cracking are correlated with the profile of residual stresses and how the performance of steel wires can be improved by modifying such a stress profile.
\end{abstract}

Keywords Residual stresses - Pearlitic steel C Cold drawing · Stress relaxation $\cdot$ Stress corrosion $\cdot$ Fatigue $\cdot$ Prestressing wires

\begin{tabular}{|c|c|}
\hline Nomenclature & \\
\hline$n$ & Diffraction order \\
\hline$d_{h k l}$ & $\begin{array}{l}\text { Lattice spacing for planes of Miller indices } \\
\text { (hkl) }\end{array}$ \\
\hline $2 \theta_{h k l}$ & Scattering angle \\
\hline$\varepsilon_{h k l}$ & $\begin{array}{l}\text { Longitudinal strain for a given (hkl) set of } \\
\text { planes }\end{array}$ \\
\hline
\end{tabular}

\begin{tabular}{|c|c|}
\hline$d_{h k l}^{0}$ & $\begin{array}{l}\text { Stress-free lattice spacing of the (hkl) } \\
\text { reflection. }\end{array}$ \\
\hline$\sigma_{0,2}$ & Yield stress \\
\hline$\sigma_{\max }$ & Tensile strength \\
\hline$R=\sigma_{\min } / \sigma_{\max }$ & Nominal stress ratio in fatigue \\
\hline
\end{tabular}

\section{Introduction}

Pearlitic cold-drawn wires are the active tendons in prestressed concrete structures and support the tensile stresses in suspension and stayed bridges. They are also the main ingredient in the tyre industry, as reinforcing steel cords. The mechanical behavior of the wires, particularly their tensile strength and toughness, is mainly controlled by the lamellar microstructure resulting from severe cold-drawing. In addition, non-uniform plastic deformation associated with drawing will produce residual stresses. If these stresses are tensile at the wire surface (where the damage processes usually begin) the durability may be compromised. This is not exclusive to cold-drawn wires, though it can be applied to many other materials as well. Consequently, it is very important to ascertain the residual stress state in prestressing steel wires.

The role of the microstructure on the mechanical properties of these steels is well known and documented (see, for example, [1-4] and references therein). However, this is not the case as regards residual stresses and its influence was acknowledged some time ago. Nonetheless, difficulties in experimental measurement and numerical modeling hampered the development of quantitative correlations between the presence of residual stresses and mechanical performance. Consequently, published results for these particular steels were barely quantitative (see, for example, [4-6] and references therein). 
Work carried out in this field over the last years [7-11] has shown that it is now possible to obtain reliable quantitative residual stress values and, in addition to this, to compute numerically residual stresses by modeling the cold-drawing process. Moreover, these results have been successfully correlated with the mechanical performance and durability of these steels, particularly with fracture due to hydrogen embrittlement. The purpose of this paper is to update and summarize these results, and will mainly focus on the author's contributions to this field. For this purpose, the paper is divided in two sections. The first one deals with the possibilities and limitations of residual stress characterization in prestressing steel wires. At present, residual stress can be measured almost routinely by X-ray diffraction at the surface of polycrystalline materials. However, in-depth information with laboratory diffractometers is rather limited in steel due to absorption. If electropolishing is used, residual stresses can be measured up to approximately half a millimeter from the surface, though corrections for layer removal must be applied. Consequently, while this technique will not provide the complete stress profile, it still can be used to check experimental measurements by neutron or highenergy synchrotron at the wire surface. In such a way, the mechanical behavior of prestressing wires can be optimized with this tool. In addition, careful monitoring of the residual stresses would allow the design of new post-drawing treatments with the aim of improving the durability in aggressive environments. As a consequence, the measurement and control of the residual stresses in cold-drawn wires could be part of the standards in the coming years. At the present moment, the Spanish Code for Structural Concrete approved in 2008 [12] requires that wires and cables for prestressed concrete will have axial residual stresses lower than $50 \mathrm{MPa}$ at the surface. It is expected that similar ideas will be implemented in the new Model Code of the International Prestressing Federation (FIP) in the near future. The second section is devoted to explaining the influence of residual stresses on the mechanical behavior of prestressing steel wires. The mechanical performance can be improved by modifying the residual stress profile resulting from colddrawing; in particular, the tensile, stress relaxation, fatigue and hydrogen embrittlement behavior.

\section{Characterization of Residual Stresses in Prestressing Steel Wires}

The most powerful non-destructive procedure to measure residual stress in polycrystalline materials is based on diffraction, either using X-rays (laboratory or synchrotron sources) or neutrons (produced in nuclear reactors or spallation sources). When a neutron or X-ray beam reaches a polycrystalline material, it is scattered and a constructive interference takes place for every set of lattice planes at certain scattering angles, obeying Bragg's Law [13]:

$n \lambda=2 d_{h k l} \sin \theta_{h k l}$

where $\mathbf{n}$ is the diffraction order, $\mathrm{d}_{\mathrm{hkl}}$ is the lattice spacing for planes of Miller indices ( $\mathrm{hkl}$ ), that are perpendicular to the scattering vector, and $2 \theta_{\mathrm{hkl}}$ is the scattering angle. Hence, the lattice spacing can be computed by simply measuring the angle at which the reflection occurs for a given wavelength. The strain for a given (hkl) set of planes can be obtained from the variation in d-spacing:

$\varepsilon_{h k l}=\frac{d_{h k l}-d_{h k l}^{0}}{d_{h k l}^{0}}$

where $\varepsilon_{h k l}$ is the longitudinal strain in the direction of the scattering vector, and $d_{h k d}^{0}$ is the unstressed lattice spacing of the hkl reflection. The stress, under the assumption of a linear elastic behavior, is then computed through the appropriate elastic model using suitable values for the elastic constants.

If the material is polyphasic, this procedure can be employed for each individual phase. In this way, the total residual stress (also called macro residual stress) can be obtained from the individual phase stresses.

Wires for prestressing concrete are made from colddrawn eutectoid steel (typical chemical composition: $0.8 \mathrm{C}, 0.6 \mathrm{Mn}, 0.2 \mathrm{Cr}$ in mass\%). From the microstructural point of view, they are a microcomposite of alternating ferrite $(\alpha-\mathrm{Fe})$ and cementite $\left(\mathrm{CFe}_{3}\right)$ lamellae. A typical microstructure is shown in Fig. '. External load is shared between each phase and, despite the low volume fraction of cementite (around 10\%), its contribution to the overall mechanical properties of the steel is not negligible.

However, the non-destructive measurement of residual stresses in the cementite phase of severely cold-drawn prestressing wires is highly challenging. In addition to the relatively low volume fraction of cementite (only 10\%), its orthorhombic structure spreads the scattering intensity into a large number of Bragg reflections. Moreover, the most intense cementite reflections overlap with the ferrite ones and most cementite peaks are hidden in the background of the diffractogram. This is due to both the low volume fraction of cementite and the peak broadening caused by elastic and plastic strains associated with cold-drawing [10, 14]. Consequently, the macro residual stress cannot be easily computed in this case because the cementite stress is usually lacking.

A number of studies have been carried out to measure residual stresses in the ferrite phase of cold-drawn steels by $\mathrm{X}$-ray diffraction [15-17]. However, due to the low penetration of conventional X-rays in steel, measurements only give information about the stresses near the surface layers. 
Fig. 1 SEM image of the typical microstructure of cold-drawn eutectoid steel wire: (a) transverse cross-section and (b) longitudinal section. The drawing direction (parallel to the rod axis) is perpendicular to the paper in (a) and lies on the paper (vertical direction) in (b)
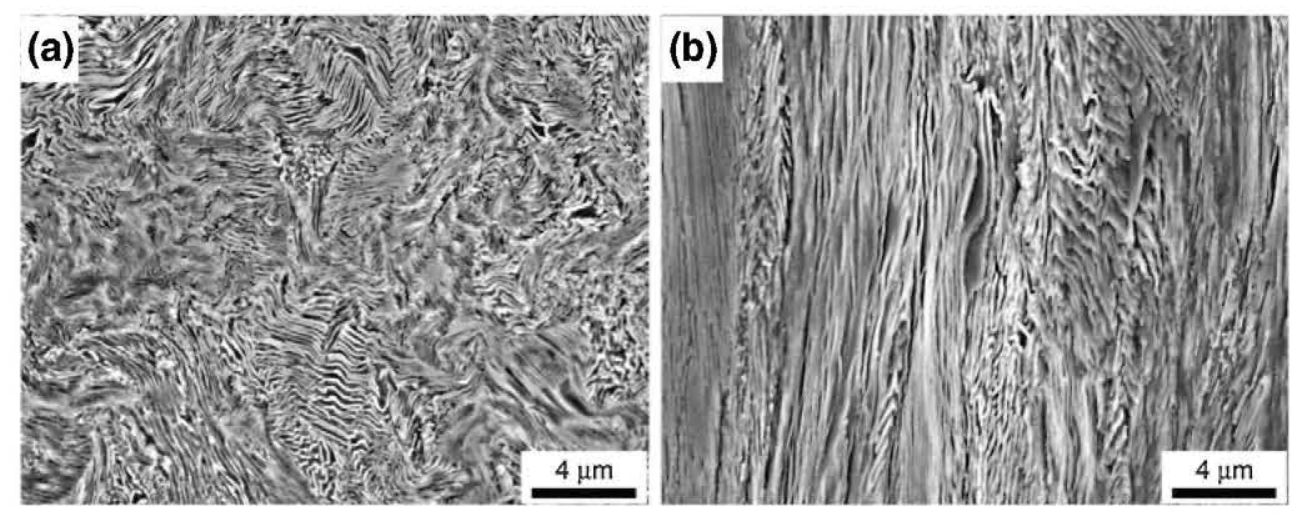

Some authors have also measured residual stresses in cementite by X-ray diffraction [18-20], neutron diffraction [7, $9,21,22]$ and high-energy synchrotron radiation [10, 14]. Cementite stresses are frequently averaged over the whole cross-section of the sample, in an attempt to improve the poor peak statistics. For example, Van Acker et al. [7] obtained ferrite and cementite stress values averaged over the cross-section of thin wires (cold-drawn from 3.22 to $1.22 \mathrm{~mm}$ ) and inferred strain profiles using a layer removal technique and subsequent corrections for stress relaxation.

In addition to experimental measurements, numerical simulations of the drawing process have been performed to obtain the residual stresses [23-25]. With this technique, the residual stress field can be obtained in all points of the cross section of the wire. However, experimental validation of the calculated residual stress profiles is usually lacking, because accurate in-depth measurements are not always available. In addition, most numerical simulations assume an isotropic mechanical behavior of the wires and consequently use a simplified von Mises yield criterion in the finite element models. However, it has been shown in the literature that the mechanical behavior of cold-drawn eutectoid steel wires is highly anisotropic. This is due to the development of a $<110>$ fiber texture in the ferrite phase and to the progressive alignment of the cementite lamellae along the drawing direction $[11,15,26]$. This mechanical anisotropy may have a remarkable effect on the deformation processes and the forces involved in cold drawing as well as on the final residual stress profile [27-29]. Consequently, numerical simulations need to be supported by experimental measurements and the material behavior must be adequately modeled in order to obtain residual stress values which can be used for quantitative purposes.

An important research effort has been undertaken in the last years by the authors for the calibration of experimental and numerical techniques to characterize residual stresses in prestressing steel wires. The research plan was divided in two phases. First, laboratory specimens were manufactured from ferritic (single phase) and pearlitic (two phases) steel rods. Once the experimental techniques and numerical modeling tools were tuned with these specimens, the second phase was developed. In this case, commercial wires for prestressing concrete, i.e. cold-drawn eutectoid steel, were investigated. The results corresponding to the first phase are summarized below.

Measurements by laboratory X-rays, neutron and synchrotron radiation and numerical simulations were performed on rods specially fabricated for this purpose $[10,17,29,30]$. To this end, two different steel rods, ferritic (single phase) and pearlitic (two phases), of $20 \mathrm{~mm}$ diameter were prepared and subjected to one drawing pass under precisely controlled conditions. The aim of using such a large diameter was to obtain a large cross section. This allows a detailed residual stress profile to be measured by neutron or high-energy synchrotron diffraction along the diameter. Additionally, to avoid any change in the residual stress pattern generated by drawing, the rods were kept straight during the whole process. The main results of this work are explained below.

\section{a) Ferritic (Single Phase) Rods}

Straight rods $(20 \mathrm{~mm}$ diameter and $6 \mathrm{~m}$ length) of ferritic steel were specially produced for this research by Saarstahl AG (Völklingen, Germany). The rods were cold-drawn in one pass to a final diameter of $18 \mathrm{~mm}$ (a $20 \%$ reduction in section). Die geometry was the following: final diameter $17.91 \mathrm{~mm}$, bearing length $6.36 \mathrm{~mm}$ and die inlet angle $2 \alpha=15.36^{\circ}$. Bars were kept straight during the whole process.

Residual stress profiles were measured by neutron diffraction (ND) along the rod diameter. Measurements were performed with the REST diffractometer, at NFL-Studsvik (Sweden). Calibration was performed with a standard iron powder. The $110 \alpha$-Fe reflection was chosen for the research, which produces a Bragg peak at about $2 \theta=49.7^{\circ}$ for the selected wavelength. Strain scanning was carried out along one diameter by measuring one point every $1.5 \mathrm{~mm}$. Gauge volume was: $1.5 \times 3 \times 1.5 \mathrm{~mm}^{3}$. Experimental details are given elsewhere [30].

Residual stresses were measured at a number of points at the rod surface by X-ray diffraction (XRD). The measurements 
were performed with a Rigaku Strainflex analyzer $(30 \mathrm{kV}$, $8 \mathrm{~mA}, \mathrm{CrK} \alpha$ radiation, $\lambda=2.2909 \AA$ ). The $\alpha$-Fe reflection under study was (211), that produces a Bragg peak at $2 \theta=156.1^{\circ}$ for the mentioned wavelength. The $\sin ^{2} \psi$ method was employed [30]. The residual stresses at the rod surface in different generatrices were approximately constant, in agreement with the expected axisymmetric stress state after colddrawing.

In order to check the experimental values with numerical predictions, the stress distribution in the rod after drawing was computed. A numerical model using the code ABAQUS was developed for this purpose [31]. An elastoplastic law with strain hardening was chosen to model the rod behavior. The constitutive equation employed, as the initial data of the model, was the stress-strain curve of the ferritic steel before drawing, measured in the laboratory. The drawing process was simulated by forcing the wire to pass through the die and imposing the displacement of the front end of the wire. The die was modeled as an elastic material. The contact between the wire and the die was reproduced with a Coulomb friction coefficient (ranging from 0.01 to 0.2 ). Residual stresses were calculated at the end of the process, when the whole rod had passed through the die, in a zone where the stationary state had been reached. Starting and final parts of the rod were not considered for this purpose.

The experimental results (neutron and $\mathrm{X}$-ray diffraction) are compared in Fig. 2 along with the numerical simulations [30]. A very good correlation between experimental and numerical results was obtained, giving additional validation to both techniques. Furthermore, the residual stress distribution

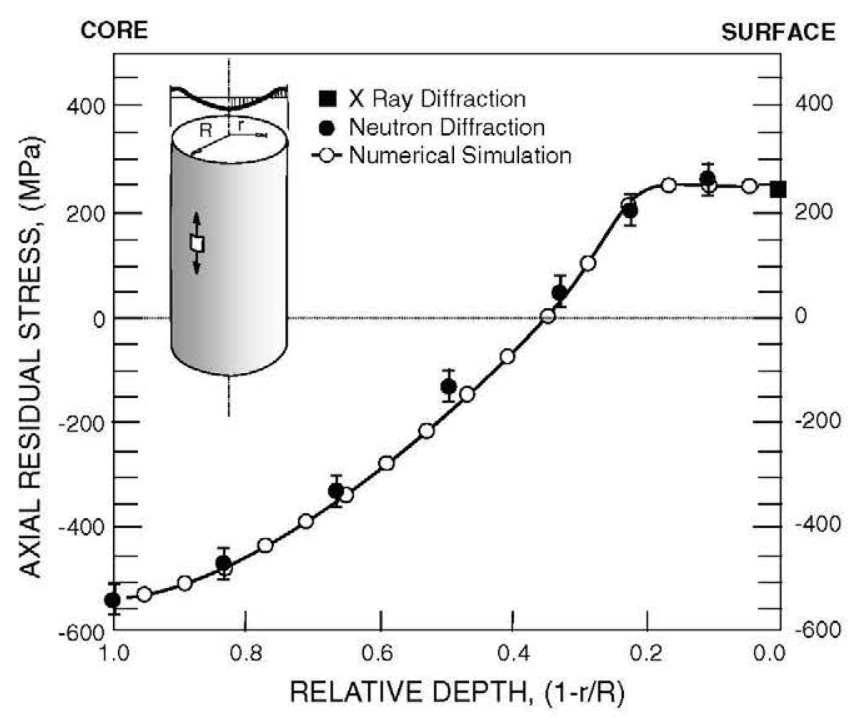

Fig. 2 Axial residual stresses in a ferritic (single phase) steel rod after one drawing pass. Residual stresses measured by neutron and X-ray diffraction are compared with numerical simulations [30] (tensile at the surface, compressive at the centre) agrees with the experience of steelmakers.

b) Pearlitic (Two Phases) Rods

Straight bars ( $20 \mathrm{~mm}$ diameter and $6 \mathrm{~m}$ length) of pearlitic steel were specially produced for this research by Saarstahl AG (Völklingen, Germany). The chemical composition (in weight percentage) of the steel was: $0.75-0.8 \% \mathrm{C}, 0.15-$ $0.35 \% \mathrm{Si}, 0.6-0.9 \% \mathrm{Mn},<0.025 \% \mathrm{P},<0.025 \% \mathrm{~S}, 0.2-0.06 \%$ $\mathrm{Al}$, resulting in approximately $10 \% \mathrm{Fe}_{3} \mathrm{C}$ in volume. The rods were cold-drawn in one pass to a final diameter of $18 \mathrm{~mm}$ (a $20 \%$ reduction in section). Die geometry was precisely measured: final diameter $17.91 \mathrm{~mm}$, bearing length $6.36 \mathrm{~mm}$ and the die inlet angle $2 \alpha=15.36^{\circ}$. Again, bars were kept straight during the whole process.

Residual stress profiles across the section of cold-drawn pearlitic steel rod specimens were determined for both the ferrite and cementite phases. In this case, cementite diffraction peaks could be observed because the rods were not severely drawn (only one pass, approximately $20 \%$ reduction in section) and a highly powerful synchrotron source was used. High-energy synchrotron radiation was employed for this purpose. The experiments were carried out at the ID15A beamline of the ESRF (Grenoble, France). Strain scanning was performed along a complete rod diameter at $0.75 \mathrm{~mm}$ steps. A pseudo-Voigt function was used for analysis of the $\{110\}$ reflection of the ferritic phase. Strain scanning in the cementite phase was performed using the $\{122\}$ reflection. The stress-free lattice parameter for ferrite was measured from iron filings and for cementite was calculated by assuming the self-equilibrium hypothesis (details are given in [10]). Residual macrostresses in the pearlitic material were determined by the stress experimentally measured in each phase, weighted with their relative percentages (rule of mixtures, in this case $90 \%$ ferrite and $10 \%$ cementite). Ferrite and cementite residual stresses in the axial direction are depicted in Fig. 3 together with the calculated macrostress profile [10]. To the authors' knowledge, this is the first time that a complete residual stress profile has been reported in both phases (ferrite and cementite) of a cold-drawn eutectoid rod.

The numerical model used for the ferritic rods was also used to simulate the cold-drawing in this case. However, a correction was employed to include the anisotropy of drawn pearlite. As a first approximation to represent the anisotropy, the Hill yield criterion was chosen. It is an extension of the von Mises criterion and can be expressed in Cartesian components as:

$$
\begin{aligned}
f(\sigma)= & {\left[A\left(\sigma_{22}-\sigma_{33}\right)^{2}+B\left(\sigma_{33}-\sigma_{11}\right)^{2}+C\left(\sigma_{11}-\sigma_{22}\right)^{2}\right.} \\
& \left.+2 D \sigma_{23}{ }^{2}+2 F \sigma_{31}{ }^{2}+2 G \sigma_{12}{ }^{2}\right]^{1 / 2}
\end{aligned}
$$




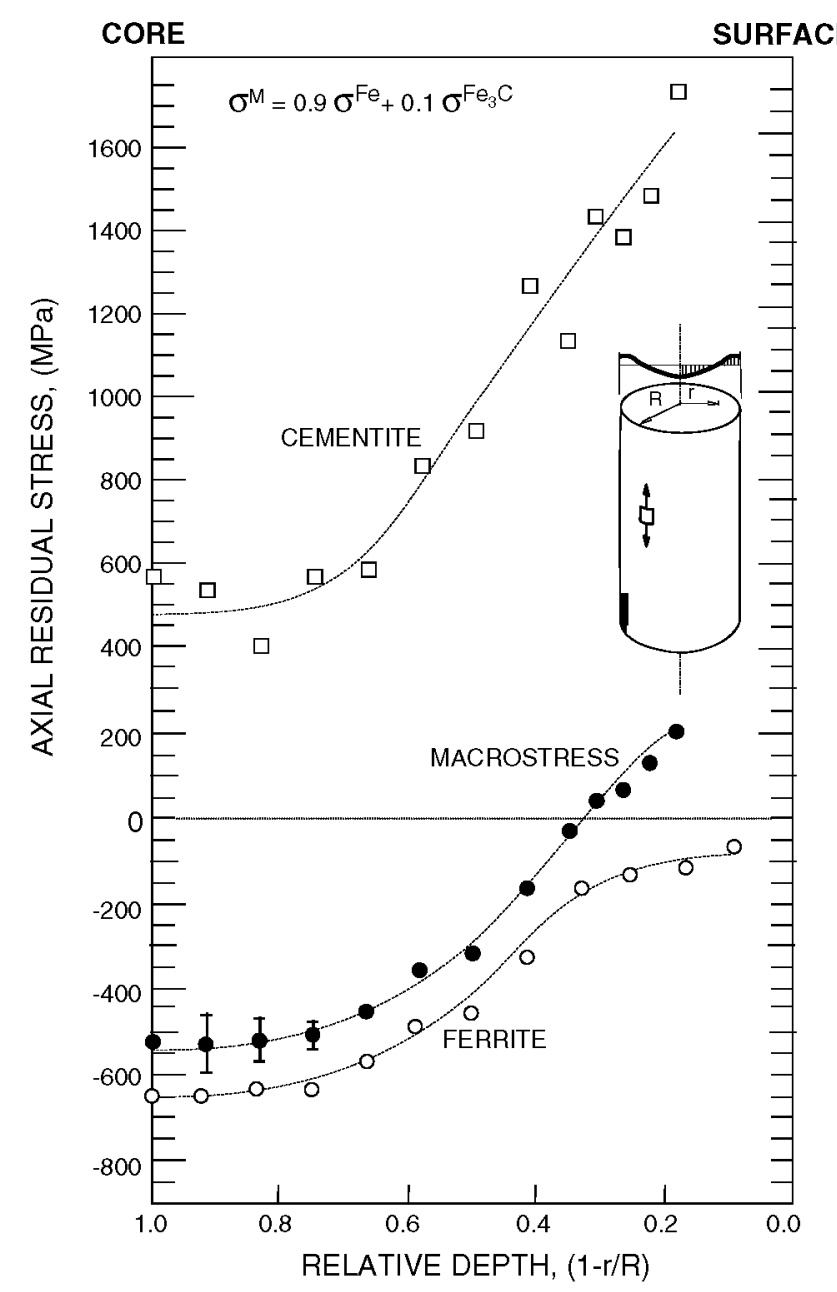

Fig. 3 Axial residual stresses in the ferrite and cementite phases of a eutectoid steel rod after one drawing pass as measured by synchrotron radiation. Macrostresses were computed from the phase stresses weighted with their relative volume fractions $(90 \%$ ferrite, $10 \%$ cementite). In this case the lines only serve as a guide for the eye. Higher error bars near the rod core are due to gauge volume effects at the low scattering angle employed $\left(2 \theta=3.5^{\circ}\right)[10]$

where the parameters $\mathrm{A}, \mathrm{B}, \mathrm{C}, \mathrm{D}, \mathrm{F}$ and $\mathrm{G}$ are referred to the yield stresses in the different directions. In this work, a user's subroutine in ABAQUS was defined to change the yield stresses in the different planar directions according to the progressive alignment of cementite lamellae $[29,31]$. The rod before drawing was considered isotropic and, to obtain an idea of the anisotropic level of the final wire, several hardness tests were carried out in different directions.

The experimental results and finite element simulations for the macro residual stresses are compared in Fig. 4 [29]. The agreement between experimental and numerical results is remarkable. The results of the finite element simulation without anisotropy are also depicted in Fig. 4. It is shown that taking into account the anisotropy does not change the

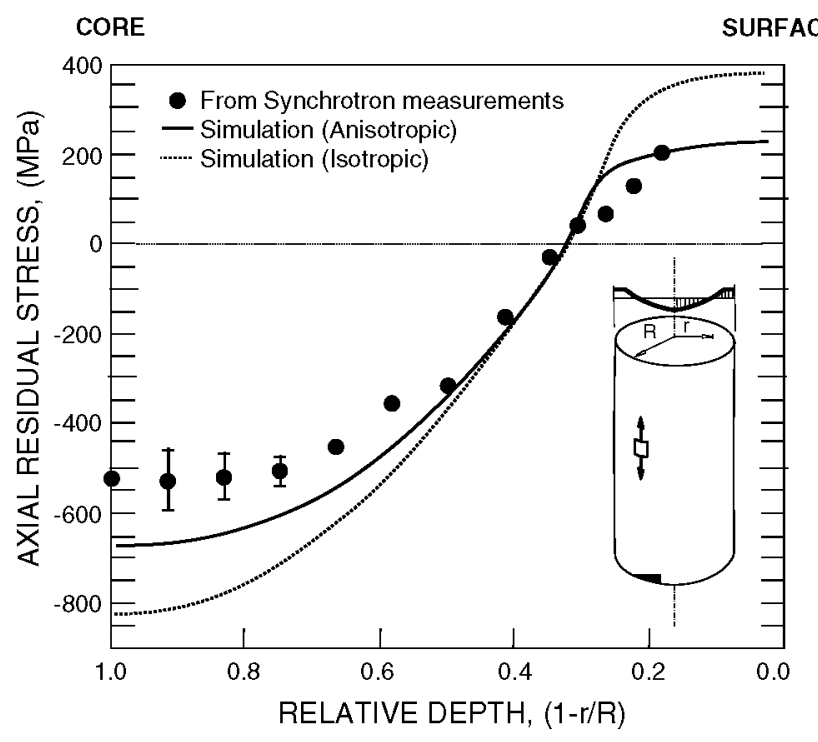

Fig. 4 Axial residual stresses in a eutectoid steel rod (two phases) after one drawing pass. A comparison is shown between the residual macrostresses calculated from the finite element simulation and those computed from the synchrotron measurements. The results of the finite element simulation without anisotropy are also shown. Higher error bars near the rod core are due to gauge volume effects at the low scattering angle employed $\left(2 \theta=3.5^{\circ}\right)[29]$

shape of the residual stress profiles, but the numerical model without anisotropy overestimates the real values of residual stresses. These differences were clear even after one drawing pass; thus, it seems that they would be significant for heavily-drawn steel wires, where the anisotropy level would be higher.

c) Summary: Present Possibilities and Limitations of Residual Stress Assessment in Prestressing Steel Wires

As explained above, the authors made an effort to assess the residual stress state in carefully fabricated "laboratory" rods. Once the experimental and numerical techniques were demonstrated to work, the following step was to apply these techniques to commercial steel wires. Residual stress measurements were carried out by neutron diffraction in prestressing wires with differing post-drawing treatments $[26,32]$. In such a way, the influence of temperature and tensile stress-during post-drawing treatments-on the resulting residual stress state was ascertained. It was found that the treatments with lower tensile stress (i.e. stretching at less than half the rupture load) or lower temperature (below $400^{\circ} \mathrm{C}$ ) were not particularly effective in reducing the residual stresses. However, when the temperature (up to $460^{\circ} \mathrm{C}$ ), or especially the force (up to 0.64 times the rupture load) were increased, all residual stress components became almost constant and slightly compressive in the ferrite phase [32]. 
The accurate measurement of residual stress fields in heavily cold-drawn steel wires is a challenging task. The main difficulties and limitations are the following:

- The low intensity of the cementite peaks (hardly distinguishable from the background) prevents strain scanning in this phase. The peak to background ratio may become so small that the peaks are hidden in the background. In addition, the most intense ones overlap with ferrite reflections. Consequently, residual stresses in the cementite phase of heavily cold-drawn steel wires are extremely difficult to obtain by diffraction methods. On the other hand, residual stresses can be obtained in ferrite and it is possible to estimate the average contribution of cementite (from self-equilibrium of residual stresses). In any case, ferrite stresses are useful to establish comparisons among different material treatments. However, the authors would argue that a method could be developed to estimate the contribution of cementite by applying external load while simultaneously measuring ferrite strain by diffraction [21]. In such a way, macro residual stresses could also be obtained in this case. Another interesting alternative to solve this problem was recently used by Yang et al., combining $X$-ray diffraction with the layer removal technique $[33,34]$. This way they obtained residual stress profiles in the ferrite phase of cold-drawn eutectoid wires. The resulting profiles follow the trends observed by using neutron and synchrotron diffraction, and reported by the authors $[10,26]$, although the measurement errors are considerable for the values near the wire core, particularly along the hoop direction [33]. In a diffraction experiment, the interplanar lattice spacing is calculated from the measured peak position. The residual strain is calculated by using a reference value which represents the stress-free configuration. This is a critical issue in achieving accurate results, especially with neutron and synchrotron diffraction, given that a plane stress state cannot be assumed (as is usually the case with laboratory X-rays). In fact, the stress-free lattice spacing must have accuracy greater than $0.01 \%$. In such a way, the error in strain would be around $0.01 \%$. This would result in approximately $20 \mathrm{MPa}$ uncertainty for steel (if the Young's modulus is taken as $200 \mathrm{GPa}$ ). Several methods have been proposed to obtain this parameter with the authors having obtained good results with stressrelieving techniques. Several cuts were carried out by electro-discharge machining which left isolated parallelepipeds in the wire sample. The unstressed lattice spacing employed was an average of the results corresponding to the different parallelepipeds [32]. Again, this is not a crucial issue if what is sought is comparison of the effectiveness of different treatments of the same material.
- Heavily cold-drawn steel wire is noticeably anisotropic. This is due to the development of a significant $<110>$ fiber texture in the ferrite and the progressive alignment of the cementite plates. As a consequence, the interpretation of residual stress measurements (especially with laboratory X-ray diffraction) is difficult due to both elastic and plastic anisotropy. Several authors have determined the relationship between measured lattice strains and average residual stresses in highly-textured materials [see references [35-38]; a review about this issue can be found in [39]]. However, this has only been applied to the ferrite phase of small diameter wires [16]. Nothing is said about the cementite phase, although its influence on the mechanical behavior of the wire is of significant importance. Consequently, the authors decided to modify their finite element model to include the anisotropy of the bulk material by using the Hill criterion. Although this is a simple approach, the authors have shown that if the anisotropy on the mechanical behavior of the wire is not considered, the finite element simulations overestimate the actual residual stress values [29]. A more refined approach would involve using crystal plasticity models to evaluate the effect of texture on the anisotropy of the stress state $[40,41]$.

- Most of the wires are subjected to bending (coiling) and unbending (straightening) processes. This may influence the axisymmetric residual stress state resulting from "ideal" cold-drawing. Consequently, it would be advisable to perform residual strain scanning measurements - by neutron or synchrotron diffraction-along several diameters of a given cross-section of the wire. However, this is usually not possible due to beam-time limitations. Thus, it would be interesting to choose the diameter corresponding to the bending plane, where the axial strains would present their maximum values (both tensile and compressive). Previous surface residual stress measurements by X-ray diffraction would provide valuable data to characterize the most endangered areas of the wire (i.e. those with the highest residual stresses at the surface).

The authors' results have shown that, despite certain limitations, diffraction methods provide a compelling tool for the control of residual stress in prestressing steel wires. By measuring residual stress it was possible to assess the effect of the different post-drawing treatments, and hence optimize the process parameters [26, 32].

Although neutron and synchrotron sources are highly powerful (because they can provide information on the triaxial residual stress state in the bulk of materials), the access to them is limited. However, commercial X-ray diffractometers are available in many laboratories. While they can only measure residual stresses at the wire surface, this 
information is of significant value since some aspects of the mechanical behavior (such as stress corrosion or fatigue) depend mainly on what happens at the wire surface, as will be explained later.

\section{Effect of Residual Stresses on Mechanical Properties}

The influence of residual stresses on the mechanical properties requested by standards for commercial steel wires for prestressing concrete (tensile, stress relaxation, fatigue and stress corrosion tests) is summarized in this section.

Wire Types according to Their Residual Stresses at the Surface

Prestressing steel wires can be divided in three groups according to their residual stresses at the surface (which are measurable by X-ray diffraction), as shown in Fig. 5 [31]:

a) As-drawn (tensile residual stresses at the surface): the term "as-drawn" refers to the wires manufactured by cold-drawing, following a commercial procedure. These wires, without any post-drawing treatment, were found to have tensile residual stresses at the surface and compressive ones in the core.

b) Stabilized (negligible residual stresses at the surface): different procedures were devised by the manufacturers to alleviate residual stresses generated by cold-drawing. The normal procedure, called stabilizing, is a thermomechanical treatment based on a combination of heating and stretching of the wire (the actual parameters of this treatment depend on each producer). Stabilized wires, also called "low relaxation wires" because of their very good behavior in the stress relaxation test, were obtained by applying the stabilizing treatment to the as-drawn wires, and are the kind currently used in prestressed concrete structures. As can be seen in Fig. 5, this treatment is highly effective in removing the residual stresses generated by drawing.

c) Rolled wires (compressive residual stresses at the surface): The third set, termed "rolled", can be obtained by rolling the surface (see, for example, [42] for a description of this procedure). This produces a small plastic deformation on the wire surface, comparable to a "massage". Compressive residual stresses can be induced on the wire surface by this procedure. A small plastic deformation on the wire surface, due to the rolling procedure, induces compressive residual stresses which are balanced by tensile ones at the wire core (see Fig. 5). The effect of this process is similar to the use of a specific last drawing die, yielding a very small reduction of area [31].

\section{Tensile Test}

Residual stresses may change the shape of the stressstrain curve of the wires obtained in a tensile test [43, 44]. During a tensile test for a wire without residual stresses, the stress distribution is uniform along the cross section (Fig. 6(a)); initially the stress remains within the elastic regime and finally it reaches a yield value and from this point the stress-strain curve is no longer a straight line.

In a tensile test on an as-drawn wire (with residual stresses), the stress distribution is not uniform across the section, as is shown in (Fig. 6(b)). Upon loading, stress increases and the first yielding appears on the surface where initially there were tensile residual stresses. This local plastification produces the loss of linearity in the stress-strain curve at an early point. As load increases, yielding extends towards the wire centre and the stress-strain curve starts deviating from a straight line. It should be noted that this
Fig. 5 Typical profiles of residual stresses (in the axial direction) along the wire diameter for as-drawn (after drawing), stabilized (after a stress relieving treatment) and rolled (after a surface treatment) wires [31]
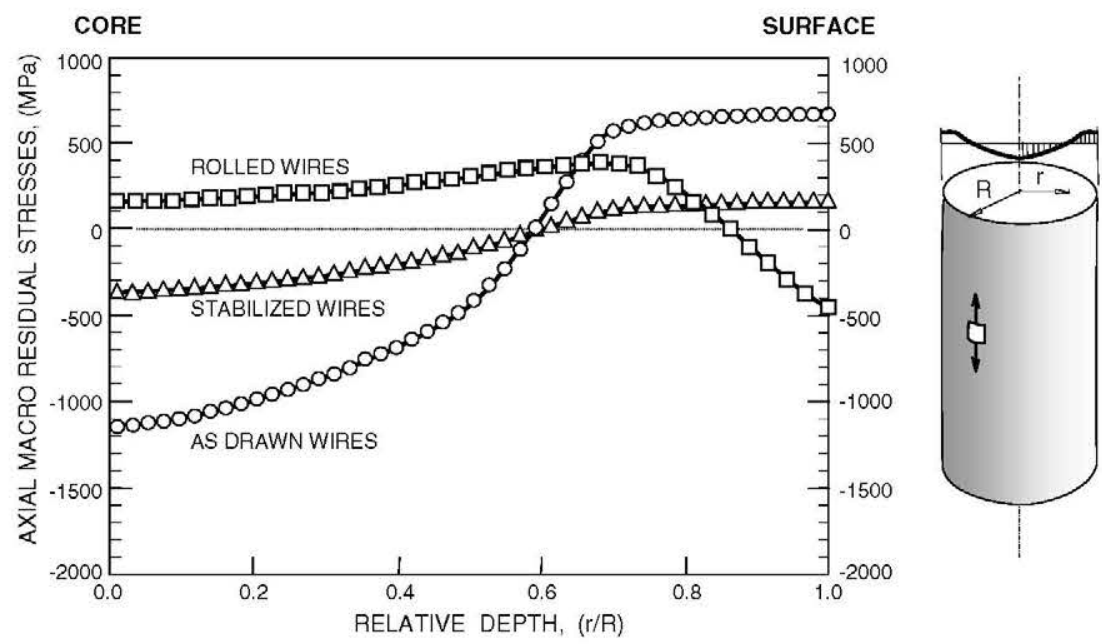

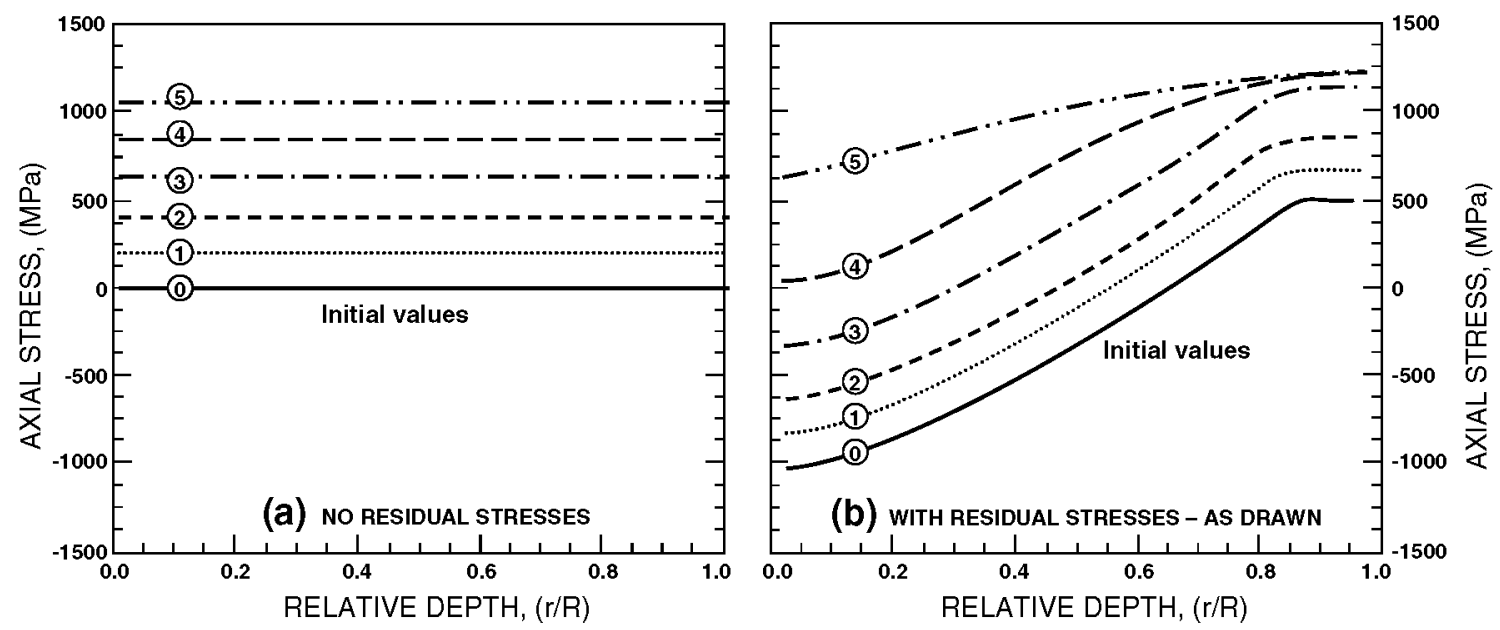

Fig. 6 Calculated axial stresses as a function of relative depth during a tensile test of a cold-drawn steel wire (elastic limit approximately equal to 1,100 MPa): (a) wire without residual stresses; (b) wire with residual stresses due to cold drawing. Stresses in both figures correspond to the same loading steps [31]

may happen with a low level of tensile stresses in the wire core or even with compressive stresses in that area (Fig. 6 (b)). A similar reasoning can be made regarding the rolled wires, though on this occasion the yield point is reached in the wire centre first.

The presence of residual stresses is reflected in the shape of the stress-strain curve. In Fig. 7 the results of a tensile test for the three kinds of wires are compared [43]. In practical terms, the presence of residual stresses (whether they are tensile at the surface or in the core) decreases the yield stress - usually measured as $\sigma_{0,2}$-as regards values without residual stresses, and has almost no influence on the tensile strength $\sigma_{\max }$. Therefore, the presence of residual stresses will affect the ratio $\sigma_{0,2} / \sigma_{\max }$, a figure that appears

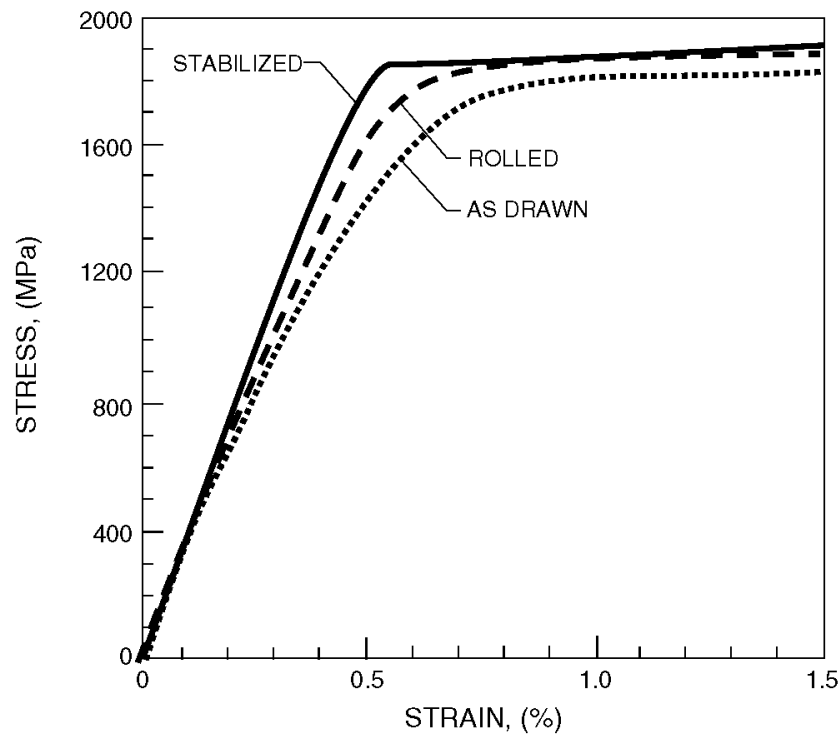

Fig. 7 Comparison between the tensile behavior of as-drawn, stabilized and rolled wires [43] in most standards for steels for prestressing concrete [45]. More precisely, these standards recommend that $\sigma_{0,2} / \sigma_{\max }$ should be in between 0.85 and 0.95 , with some suggesting optimum values of about $0.90-0.93$.

In summary, the presence of residual stresses favors the onset of yielding. The higher the residual stresses, whether tensile or compressive at the surface, the lower the yield stress in a tensile test. The ratio $\sigma_{0,2} / \sigma_{\max }$ decreases with increasing values of residual stresses. Given the deleterious effect of tensile residual stress at the surface on fatigue and stress corrosion $[5,6]$, it was reasonable to require a lower limit to $\sigma_{0,2} / \sigma_{\max }$. The ratio $\sigma_{0,2} / \sigma_{\max }$ can be increased by relieving residual stresses, a common procedure after drawing, based on thermomechanical treatments.

\section{Stress Relaxation Test}

Cold-drawn steel wires and cables are subjected to high tensile stresses in prestressed concrete structures. However, this stress decreases with time, mainly due to stress relaxation. Stress relaxation losses in steel reinforcement are of paramount importance to structural safety, given that the prestressed compressive load of the concrete is reduced. Design codes place limits to keep these losses within safe margins [45]. Stress losses are measured according to a standardized test (ASTM E328, ISO15630/3) and the values should be provided by the manufacturer for the acceptance of the steel reinforcements. Those with a stress loss smaller than $2.5 \%$ of the initial stress-after $1,000 \mathrm{~h}$ at room temperature and stressed at 0.70 of the tensile strength-are called "low relaxation" wires and are those used at present in prestressing.

It is well known that in prestressing steel the higher the initial stress the greater is the relaxation loss [46]. Furthermore, 
some researchers have studied the influence of post-drawing treatments on the stress relaxation behavior of the wires [47]. Specimens subjected to different thermomechanical treatments (applied stress and temperature) were used for this purpose. It was found that the lowest relaxation values corresponded to samples treated at the highest temperatures (around $400^{\circ} \mathrm{C}$ ) and loaded to the highest stresses (around half the tensile strength) [47]. In fact, these figures agreed quite remarkably with those provided by the authors in [32] for the best stress relieving postdrawing treatments. Although it seems clear that existing residual stresses will modify the actual stress state in the wire when it is loaded in service, there was no clue about their effect on stress relaxation when the authors started this investigation [48].

Figure 8(a) shows stress relaxation losses after $250 \mathrm{~h}$ in stabilized wires [48], with negligible residual stresses, initially loaded at different percentages of the ultimate tensile stress (from 50\% to 98\%). The losses are small at low values of initial stresses and increase suddenly when these stresses approach the yield stress (approximately $85-90 \%$ of
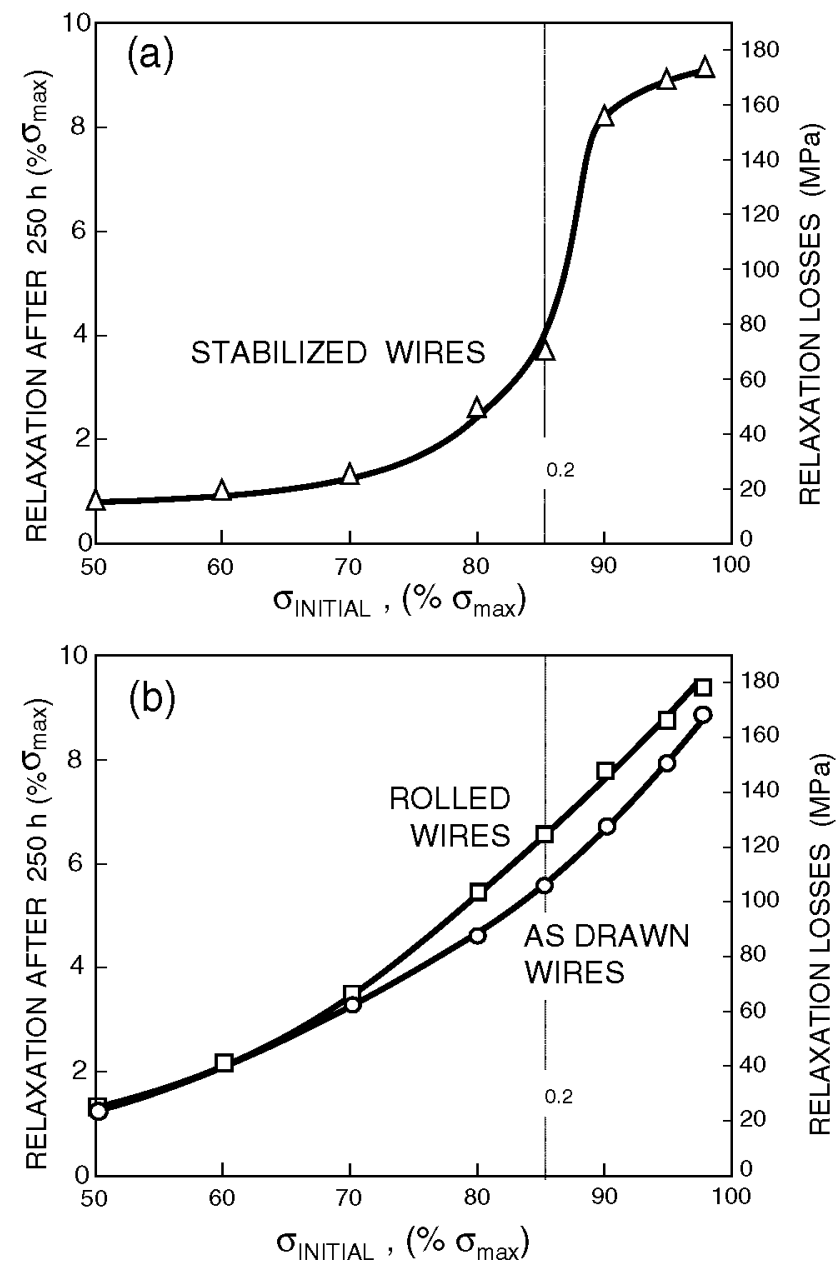

Fig. 8 Stress relaxation losses (at $250 \mathrm{~h}$ ) as a function of the initial load (both expressed as a percentage of the ultimate tensile stress): (a) stabilized wires, and (b) as-drawn and rolled wires [48] maximum load). Stress relaxation losses after $250 \mathrm{~h}$ in asdrawn and rolled wires, again loaded at different percentages of their respective ultimate tensile stresses, are shown in (Fig. 8(b)). The behavior of these two types of wireswhose residual stresses are by no means negligible - is quite different from that of stabilized wires (Fig. 8(a)).

The role of residual stresses can be explained as follows $[48,49]$. The actual stress distribution in the section of the wires during the test is significantly different in the three types of wires. For stabilized wires the stress distribution across the section is almost uniform, so the wire is subjected to the same initial load all over the cross section. For asdrawn wires, the stress distribution across the section at the beginning of the relaxation test is not uniform across the section; once loaded, the outer regions of the wire are subjected to higher stresses than the inner part, so the stress relaxation in these regions is higher, as can be inferred from (Fig. 8(a)). The stress relaxation losses of the wire are the sum of the losses produced along the whole cross-section and the effect of approaching the yield stress is not so important, because yielding does not occur at the same time over the section. Similar reasoning can explain the experimental results for the rolled wires, shown in (Fig. 8(b)). In summary, when dealing with stress relaxation losses, the behavior of the whole section is relevant. From this point of view, the best behavior is obtained for wires with small residual stresses (stabilized). The presence of residual stresses, regardless of whether they are tensile or compressive at the surface, will increase the stress relaxation losses of the wires.

Another result, which merits particular attention, is that at high initial loads the stress relaxation behavior of the three types of wires becomes very similar. At high applied stresses, the role of residual stresses is not so important because most of the wire section will have yielded and the stress gradient across the section becomes smooth, so the stress profiles across the wire sections for stabilized, asdrawn and rolled wires are almost identical. Thus, the better stress relaxation behavior of stabilized wires is lost when stressed at high loads, i.e. greater than $0.80 \sigma_{\max }$.

\section{Fatigue Test}

Standard requirements regarding the fatigue behavior of prestressing steels include specifications on the fatigue limit and the fatigue life [50]. As the development of a dominant crack from the wire surface under high-cycle fatigue occupies the major part of the fatigue lifetime, an accurate calculation of the fatigue life requires an accurate knowledge of the surface stresses, which are dependent on the external loads and on residual stresses [51].

An experimental and numerical investigation of the influence of residual stresses in cold-drawn eutectoid steels on 
the fatigue limit and on the fatigue life was undertaken some years ago [6, 52-55]. Llorca and Sanchez-Galvez [52, 53] performed fatigue tests at a constant stress range and at different nominal stress ratios $\left(\mathrm{R}=\sigma_{\min } / \sigma_{\max }\right)$ on wires with different residual stresses. Fatigue tests were also modeled numerically, as described in [6]. The fatigue life in the high stress ranges showed little influence of residual stresses. In ranges close to the threshold, fatigue behavior was strongly dependent on the residual stresses and the shape of the initial flaws. The influence of residual stresses on the fatigue threshold was important at small stress ratios.

Recent work by Katagiri et al. $[54,55]$ with cold-drawn eutectoid steel wires of $0.3 \mathrm{~mm}$ diameter showed similar results, i.e., the residual stress is one of the controlling factors of the fatigue limit (as measured by $\mathrm{S}-\mathrm{N}$ curves). The residual stress in the as-drawn wires was extremely high (around 1,000 MPa) and the fatigue limit around $780 \mathrm{MPa}$. However, when the samples were shot peened, the residual stress became compressive (around $-300 \mathrm{MPa}$ ) and the fatigue limit reached its maximum $(1,200 \mathrm{MPa})$.

\section{Stress Corrosion Test}

The combined action of the prestressing load and an aggressive environment may produce the fracture of the steel reinforcement, a phenomenon known as stress corrosion cracking. This is an important issue, both from the point of view of structural safety (loss of bearing capacity of the structure) and durability (need for costly maintenance) $[56,57]$.

There is general agreement that hydrogen embrittlement plays an important role in the environmentally-assisted cracking of eutectoid cold-drawn steels [58]. To control the susceptibility of these steels to hydrogen embrittlement, the International Federation for Prestressing Concrete (FIP) proposed a simple test - the ammonium thiocyanate test - in $1978[59,60]$. Despite its disadvantages (mainly the scattering in experimental data and the extremely aggressive environment used), it remains widely accepted for the control and acceptance of these steels [61]. In the FIP78 test, samples are loaded at $80 \%$ of their tensile strength in an aqueous solution of ammonium thiocyanate $\left(\mathrm{NH}_{4} \mathrm{SCN}\right)$ at a constant temperature of $50 \pm 1{ }^{\circ} \mathrm{C}$, and rupture times are recorded.

Several works have shown that in cold-drawn eutectoid steel wires there are two factors which influence the scattering in rupture times: the surface defects and the residual stresses at the surface region of the wires [5, 62-64]. However, until now, it has been hard to correlate the results of the FIP test with the profile of residual stresses because of the difficulties in the residual stress characterization. The advent of powerful experimental and numerical tools to characterize residual stresses has helped researchers to see this problem in a new light $[42,65]$.

Recently, the authors have found a good correlation between the residual stresses at the wire surface and the rupture times measured by the FIP78 test. The main results obtained are the following:

a. The difference in rupture times in cold-drawn eutectoid steel wires-with the same microstructure, surface quality and similar mechanical properties-seem to be associated with residual stresses. It was found that the "as-drawn" wires (with tensile residual stresses at the surface) show the lowest rupture times, as compared to those where the residual stresses are either negligible ("stabilized") or even compressive ("rolled"). This can be seen in Fig. 9 [42].

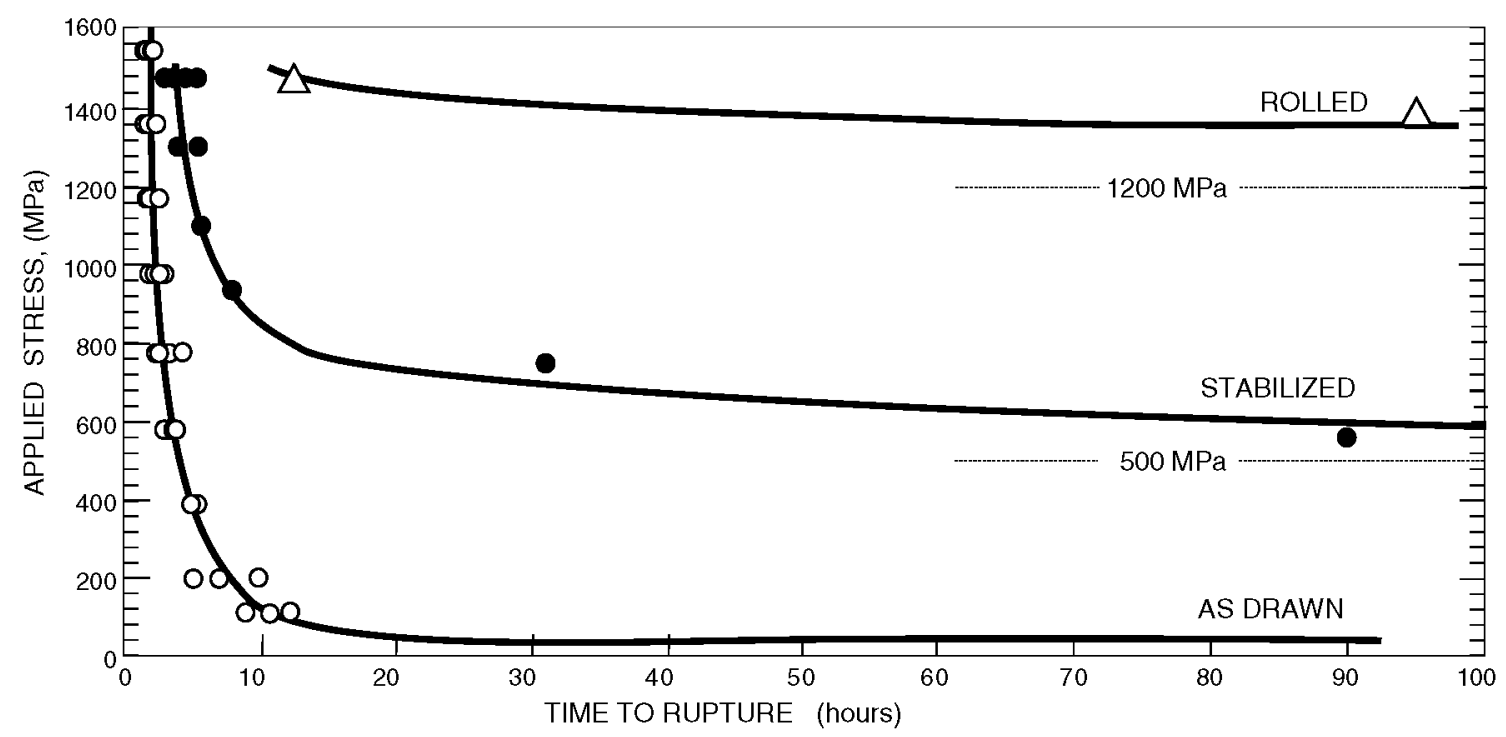

Fig. 9 Rupture times, in the $\mathrm{NH}_{4} \mathrm{SCN}$ test at different initial loads, for as-drawn, stabilized and rolled wires [42] 
b. The load used in the FIP78 test, $80 \%$ of the tensile strength (tensile strength is around 2.000 MPa for this kind of prestressing wires) may conceal the effect of residual stresses. Upon loading the wire sample, if the residual stress at the wire surface is tensile, the elastic limit will be reached first in this region. An additional increase of the testing load will not significantly change the stress at the wire surface (which will have already yielded). This effect is shown in Fig. 9, where tests at loads different from the standard one were performed in the three types of wires. If the testing load is decreased, the differences in rupture times between the wires are amplified.

c. The results from the FIP78 test show that the post-drawing treatment which produces compressive residual stresses at the surface improves in a dramatic fashion the wire behavior in aggressive environments, as can be seen in Fig. 9. This is explained by the fact that crack initiation, which is mainly controlled by what happens at the wire surface, is the dominant step in this type of test.

\section{Summary and Final Comments}

The measurement of residual stresses using diffraction techniques is at present a reliable and well established technique. Additionally, computing residual stresses after wire drawing using numerical procedures is feasible thanks to the availability of general purpose finite element analysis tools. Such advances have shown that these techniques can now be used almost routinely and that they are ready to be quoted in standards for quality control and acceptance of cold-drawn wires.

Moreover, it has been shown that residual stresses affect significantly the mechanical performance of cold-drawn wires: particularly the shape of the tensile stress-strain curve, the stress relaxation behavior, and the durability through its susceptibility to fatigue and environmentallyassisted cracking. Thanks to these findings it is now possible to justify some empirical rules established by the design codes (related with the shape of the stress-strain curve, the relaxation behavior or with durability) and based on previous experience.

A better understanding of the residual stress profiles may help in improving the performance of cold-drawn steel wires. Residual stresses are not always detrimental; it was shown that surface compressive residual stresses enhance durability (with respect to fatigue or stress corrosion cracking) albeit its stress relaxation worsens. It may happen that for each specific application a suitable profile of residual stresses should be selected. It is believed that these results may provide valuable insights for producers and researchers in this field.
Acknowledgements The authors gratefully acknowledge the support of the Ministerio de Fomento, by means of the "Durability of prestressed concrete tendons" grant, and the Ministerio de Educación, through the FEDER 2FD1997-1513 grant. This work was also supported by the CICYT MAT 2003-00836 and ENE2005-06478/CON projects. The present work was conducted within the framework provided by the projects DUMEINPA, sponsored by the Comunidad de Madrid, Spain, and SEDUREC, integrated in the Spanish national research programme CONSOLIDER-INGENIO 2010. The authors are indebted to Dr. María Martínez, Dr. Mar García and Dr. Federico Mompeán for their contribution to the neutron and synchrotron measurements, and Dr. Luis Caballero for the stress corrosion tests. Help and useful comments from Mr. Luis del Pozo, Emesa Trefilerías, and Mr. Javier del Río, from Bekaert, are also acknowledged.

\section{References}

1. Embury JD, Fisher RM (1966) The structure and properties of drawn pearlite. Acta Metall 14:147-159

2. Pickering FB (1978) Physical Metallurgy and the Design of Steels Applied Science Publishers Ltd., London

3. Langford G (1977) Deformation of pearlite. Metall Trans A 8:861875

4. Taleff EM, Lewandowski JJ, Pourladian B (2002) Microstructureproperty relationships in pearlitic eutectoid and hypereutectoid carbon steels. JOM 54:25-30

5. Elices M, Maeder G, Sánchez-Gálvez V (1983) Effect of surface residual stress on hydrogen embrittlement of prestressing steels. $\mathrm{Br}$ Corros J 18:80-81

6. Llorca J, Sánchez-Gálvez V (1987) Numerical determination of the influence of residual stresses on fatigue. Proceedings of the International Conference in Computational Plasticity, Barcelona, Pineridge Press Limited, pp 1123-1136

7. van Acker K, Root J, van Houtte P, Aernoudt E (1996) Neutron diffraction measurement of the residual stress in the cementite and ferrite phases of cold-drawn steel wires. Acta Mater 44:4039-4049

8. He S, Van Bael A, Li SY, Van Houtte P, Mei F, Sarban A (2003) Residual stress determination in cold drawn steel wire by FEM simulation and X-ray diffraction. Mater Sci Eng, A 346:101-107

9. Kanie A, Tomota Y, Torii S, Kamiyama T (2004) Elastic strains of cementite in a pearlite steel during tensile deformation measured by neutron diffraction. ISIJ Int 44:1952-1956

10. Martinez-Perez ML, Mompean FJ, Ruiz-Hervias J, Borlado CR, Atienza JM, García-Hernandez M, Elices M, Gil Sevillano J, Peng RL, Buslaps T (2004) Residual stress profiling in the ferrite and cementite phases of cold-drawn steel rods by synchrotron X-ray and neutron diffraction. Acta Mater 52:5303-5313

11. Suzuki T, Tomota Y, Isaka M, Moriai A, Minakawa N, Morii Y (2004) Strength anisotropy and residual stress in drawn pearlite steel wire. ISIJ Int 44:1426-1430

12. EHE-08, Spanish Code on Structural Concrete (2008). Ministry of Public Works, Spain. http://www.fomento.es/mfom/lang_castellano/ organos colegiados/cph/instrucciones/ehe08ingles/

13. Noyan JC, Cohen JB (1987) Residual stress measurement by diffraction and interpretation. Springer, Berlin

14. Belassel M, Ji V, Lebrun JL, Gergaud P, Francois M, Bessiere M (1994) Analysis of the mechanical behavior of materials through the 2nd and 3rd-order stress determination. J Phys IV 4:261-264

15. Willemse PF, Naughton BP, Verbraak CA (1982) X-ray residual stress measurements on cold-drawn steel wire. Mater Sci Eng $56: 25-37$

16. Zolotorevsky NY, Krivonosova NY (1996) Effect of ferrite crystals plastic anisotropy on residual stresses in cold-drawn steel wire. Mater Sci Eng, A 205:239-246 
17. Ruiz J, Atienza JM, Elices M (2003) Residual stresses in wires: influence of wire length. J Mater Eng Perform 12:480 489

18. Hanabusa T, Fukura J, Fujiwara $H$ (1969) X-ray stress measurement of the cementite phase in steels. B JSME 13:931939

19. Nishioka K, Hanabusa T, Fujiwara H (1974) Theory of the X-ray residual stress analysis. Scripta Metall 8:1349-1350

20. Nishida M, Hanabusa T, Fujiwara H (1989) Residual microstress development in two-phase materials due to tensile deformation. J JSMS 38:576-581 (in Japanese)

21. Daymond MR, Priesmeyer HG (2002) Elastoplastic deformation of ferritic steel and cementite studied by neutron diffraction and self-consistent modelling. Acta Mater 50:1613-1626

22. Tomota Y, Lukas P, Neov D, Harjo S, Abe YR (2003) In situ neutron diffraction during tensile deformation of a ferrite-cementite steel. Acta Mater 51:805-817

23. Sawamiphakdi K, Kropp PK, Lahoti GD (1990) Investigation of residual stresses in drawn wire by the finite element method. J Eng Mater Technol 112:231-235

24. Gerhardt J, Tekkaya AE (1987) Applications of the finite element method on the determination of residual stresses in drawing and extrusion. Computational Plasticity, Proceedings of the International Conference, Barcelona, Pineridge Press Limited, pp 10371050

25. Hamada T, Hirouchi T, Akiyama M (2000) A numerical study of temperature in a fine high carbon steel wire subjected to high speed drawing. Wire J Int June 2000:102-113

26. Ruiz-Hervias J, Luzin V, Prask H, Gnaeupel-Herold T, Elices M (2006) Effect of thermo-mechanical treatments on residual stresses measured by neutron diffraction in cold-drawn steel rods. Mat Sci Eng A 435-436:725-735

27. Gil-Sevillano J (1975) Room temperature plastic deformation of pearlitic cementite. Mater Sci Eng 21:221-225

28. Gil-Sevillano J, Van Houtte P, Aernoudt E (1978) Plastic anisotropy of pearlitic ferrite. Proceedings ICOTOM 5, Gotstein G, Lücke K. Eds. Springer Verlag, II, pp 495-504

29. Atienza JM, Ruiz-Hervias J, Martínez-Perez ML, Mompean FJ, Garcia-Hernandez M, Elices M (2005) Residual stresses in cold drawn pearlitic rods. Scripta Mater 52:1223-1228

30. Atienza JM, Martinez-Perez ML, Ruiz-Hervias J, Mompean FJ, Garcia-Hernandez M, Elices M (2005) Residual stresses in cold drawn ferritic rods. Scripta Mater 52:305-309

31. Atienza JM (2001) Residual stresses in cold drawn steel wires. Ph.D. Dissertation, Universidad Politecnica de Madrid, Spain (in Spanish)

32. Ruiz-Hervias J, Atienza JM, Elices M, Oliver EC (2008) Optimisation of post-drawing treatments by means of neutron diffraction. Mat Sci Eng A 480:439-448

33. Yang F, Jiang JQ, Fang F, Wang Y, Ma C (2008) Rapid determination of residual stress profiles in ferrite phase of cold-drawn wire by XRD and layer removal technique. Mat Sci Eng A 486:455-460

34. Yang F, Wang Y, Jiang JQ, Fang F, Ma C, Zhao KL, Li W (2008) Stress evolution of cold-drawn pearlitic steel wire subjected to uniaxial tension. Mat Sci Eng A 487:468-472

35. Dölle H, Hauk V (1978) Influence of mechanical anisotropy of polycrystal (texture) upon stress evaluation by means of X-rays. $Z$ Metallkde 69:410-417

36. Van Baal CM (1983) The Influence of Texture on the X-Ray Determination of Residual Strains in Ground or Worn Surfaces. Phys stat sol (a) 77:521-526

37. Brakman CM (1983) Residual stresses in cubic materials with orthorhombic or monoclinic specimen symmetry-influence of texture on psi-splitting and non-linear behaviour. J Appl Cryst $16: 325-340$
38. Barral M, Lebrun JL, Sprauel JM et al (1987) X-ray macrostress determination on textured material - use of the ODF for calculating the X-ray compliances. Metall Trans A 18:1229-1238

39. Hauk V (1997) Structural and residual stress analysis by nondestructive methods. Elsevier, Amsterdam

40. Dawson PR, Boyce DE, Hale R, Durkot JP (2005) An isoparametric piecewise representation of the anisotropic strength of polycrystralline solids. Int J Plast 21:251-283

41. Miller MP, Park JS, Dawson PR, Han TS (2008) Measuring and modeling distributions of stress state in deforming polycrystals. Acta Mater 56:3927-3939

42. Atienza JM, Ruiz-Hervias J, Caballero L, Elices M (2006) Residual stresses and durability in cold drawn eutectoid steel wires. Met Mater Int 13:139-143

43. Atienza JM, Elices M (2003) Influence of residual stresses in the tensile test of cold drawn wires. Mater Struct 36:548-552

44. Goes B, Gil-Sevillano J, D'Haene UD (1999) Modelling the evolution of residual stresses during tensile testing of elastoplastic wires subjected to a previous bending operation. Int J Mech Sci 41:1031-1050

45. CEB-FIP (1990) Model Code 1990, Lausanne, (1991). ASTMA421 (1991), EHE-UNE 36094 (1994), BS-2691 (1991)

46. Lin TY, Burns NH (1981) Design of prestressed concrete structures. John Wiley and Sons Eds, New York

47. Zeren A, Zeren M (2003) Stress relaxation properties of prestressed steel wires. J Mater Process Tech 141:86-92

48. Atienza JM, Elices M (2004) Influence of residual stresses in the stress relaxation of cold drawn wires. Mater Struct 37:301-304

49. Atienza JM, Elices M (2007) Role of residual stresses in the stress relaxation of prestressed concrete wires. J Mater Civ Eng 19:703707

50. CEB-FIP (1978) Model Code for concrete structures. Bulletin d'Information 124-125 F, Paris

51. McClung RC (2007) A literature survey on the stability and significance of residual stresses during fatigue. Fatigue Fract Eng Mater Struct 30:173-205

52. Llorca J, Sánchez-Gálvez V (1987) Fatigue threshold determination in high strength cold drawn eutectoid wires. Eng Fract Mech 26:869-882

53. Llorca J, Sanchez-Galvez V (1989) Fatigue limit and fatigue life prediction in high strength cold drawn eutectoid steel wires. Fatigue Fract Eng Mater Struct 12:31-45

54. Katagiri K, Sato T, Shin HS, Takahashi L, Mori H, Sasaki S, Tashiro H (1997) Effects of drawing strain and bluing on the fatigue strength of eutectoid steel wires. Fatigue Fract Eng Mater Struct 20:1677-1686

55. Katagiri K, Sato T, Kasaba K, Sasaki S, Tashiro H (1999) Effects of post-drawing treatments on the fatigue strength of eutectoid steel wires. Fatigue Fract Eng Mater Struct 22:753760

56. Taerwe L (ed) (2001) Durability of post-tensioning tendons. Proc 1st. FIB Workshop, Ghent, Belgium

57. Elsener B (Ed.) (2004) Durability of post-tensioning tendons. Proc 2nd FIB Workshop, Zurich, Switzerland

58. Enos DG, Scully JR (2002) A critical-strain criterion for hydrogen embrittlement of cold-drawn, ultrafine pearlitic steel. Metall Mater Trans A 33:1151-1166

59. FIP-78, International Federation for Prestressing (1978) Stress Corrosion Cracking Resistance Test for Prestressing Tendons. Technical Report No. 5, FIP, Wexham Springs, Slough, UK

60. ISO Standard 15630-3 (2002) Steel for Reinforcement and Prestressing of Concrete. Test Methods, Part 3: Prestressing Steel International Organization for Standardization [ISO], Geneva, Switzerland 
61. Elices M, Caballero L, Valiente A, Ruiz-Hervias J, Martin A (2008) Hydrogen embrittlement of steels for prestressing concrete: The FIP and DIBt tests. Corros 64:164-174

62. Parkins RN, Elices M, Sánchez-Gálvez V, Caballero L (1982) Environment sensitive cracking of prestressing steels. Corros Sci $22: 379-405$
63. Toribio J (1998) Role of crack-tip residual stresses in stress corrosion behaviour of prestressing steel. Constr Build Mater 12:283-287

64. Toribio J (1998) Residual stress effects in stress corrosion cracking. J Mater Eng Perform 7:173-182

65. Elices M, Ruiz J, Atienza JM (2004) Influence of residual stresses on hydrogen embrittlement of cold-drawn wires. Mater Struct 37:305-310 